\title{
Nonvalvüler Atriyal Fibrilasyon Hastalarında Dabigatran Tedavisinin Trombosit Hacim İndeksleri ve Trombosit Sayısı Üzerine Etkileri
}

\section{Effects of Dabigatran Treatment on Platelet Volume Indices and Platelet Count in Nonvalvular Atrial Fibrillation Patients}

\author{
Ferhat Özyurtlu ${ }^{1}$, Nurullah Çetin ${ }^{2 *}$ \\ ${ }^{1}$ Özel Grandmedical Hastanesi, Kardiyoloji Kliniği, Manisa, Türkiye \\ ${ }^{2}$ Manisa Celal Bayar Ünivesitesi Tıp Fakültesi, Kardiyoloji Anabilim Dalı, Manisa, Türkiye \\ email: fozyurtlu@yahoo.com, nurullahctn@hotmail.com \\ ORCID: 0000000168141254 \\ ORCID: 0000000241585469 \\ *Sorumlu Yazar / Corresponding Author: Sorumlu Yazar: Nurullah Çetin \\ Gönderim Tarihi / Received:27.03.2020 \\ Kabul Tarihi / Accepted: 15.05.2020 \\ DOI: $10.34087 /$ cbusbed.710032
}

Giriş ve Amaç: Çalışmamızda, nonvalvüler atriyal fibrilasyon tedavisinde kullanılan Dabigatranın trombosit indeksleri üzerindeki etkisini araştırmayı amaçladık.

Gereç ve Yöntemler: Çalışmamıza Ocak 2018 ve Aralık 2019 tarihleri arasında Kardiyoloji polikliniğine başvurup, non valvüler atriyal fibrilasyon tanısı ile endikasyon dahilinde dabigatran tedavisi başlanmış 69 hasta dahil edilmiştir. Hastaların dosyaları taranarak dabigatran başlanmadan önceki ve tedavi altında 6 ay sonraki laboratuar parametreleri değerlendirmeye alındı.

Bulgular: Çalışmaya 69 hasta dahil edilidi. Yaş ortalaması $69 \pm 9$ olup, hastaların \%62,3'si kadın, \%37,7'si erkek idi. Hastaların \%87'sinde hipertansiyon, \%26,1'inde diabetes mellitus, \%17,4'ünde dislipidemi mevcuttu. 6 aylık dabigatran kullanımı sonrasında, başta Mean Platelet Volume (MPV) olmak üzere, platalet sayısı ve diğer trombosit indekslerinde anlamlı bir değişiklik saptanmadı.

Sonuç: 6 aylık bir tedavi periyodunda dabigatranın MPV başta olmak üzere, trombosit sayısı ve diğer platelet indeksleri üzerinde anlamlı bir değişikliğe yol açmadığını gözlemledik. Çalışma verilerimiz ışığında Dabigatran'ın Atriyal Fibrilasyon (AF)'de inme ve tromboembolinin önlenmesinde, platelet indeksleri üzerine olan etkisinin bir anlam ifade etmediği görülmektedir.

Anahtar Kelimeler: Dabigatran, inme, mean platelet volüm, nonvalvüler atriyal fibrilasyon

\begin{abstract}
Objective: We aimed to investigate whether dabigatrane treatment does affect platelet indices in patients with nonvalvular atrial fibrillation.

Materials and Methods: 69 patients who were admitted to the cardiology outpatient clinic between January 2018 and December 2019, who were diagnosed with non valvular fibrillation and received dabigatrane treatment were included in the study. The patient's files were scanned and laboratory parameters before dabigatrane was started and 6 months after treatment were evaluated.

Results: The study included 69 patients. Mean age of the patients was $69 \pm 9$ and $\% 62,3$ of patients were woman, $\% 37,7$ were man. $\% 87$ of patients had hypertension, $\% 26,1$ had diabetes mellitus, $\% 17,4$ had dyslipidemia. After 6 months of dabigatran use, there was no significant change in platelet count and other platelet indices, especially Mean Platelet Volume (MPV).

Conclusion: In a 6-month treatment period, we observed that dabigatrane did not cause a significant change in platelet index and other platelet indices, especially MPV. In the light of our study data, it is seen that the effect of Dabigatrane on platelet indices does not make sense in the prevention of stroke and thromboembolism in Atrial Fibrillation (AF).
\end{abstract}

Keywords: Dabigatran, mean platelet volume, nonvalvular atrial fibrillation, stroke 


\section{Giriş}

Atriyal fibrilasyon (AF) erişkin popülasyonda en s1k görülen ritm bozukluğu olmakla birlikte emboli ve inme riskindeki artış nedeni ile önemli bir morbidite ve mortalite nedenidir [1]. Antikoagülan tedavi, AF hastalarında inme ve ilişkili mortaliteyi önemli ölçüde azaltır [2]. Antikoagülanlar dışındaki tedavilerin AF hastalarında mortalite üzerinde olumlu etkiler yarattığ açıkça gösterilememiştir [3, 4]. Varfarin AF'de arteryel emboli ve inmenin önlenmesinde temel antikoagülan ilaç konumunda bulunmakta iken yakın zamanda yeni nesil oral antikoagülanlar (YOAK) klinik kullanıma girmiştir. Etkilerinin hızlı başlaması ve sonlanması, ilaç veya gıda etkileşimlerinin varfarine kıyasla oldukça az olmas1, sabit dozlarda varfarin gibi sik laboratuar kontrolü gerektirmeden tahmin edilebilir bir antikoagülan etkiye sahip olmaları YOAK'ları varfarine tercih edilebilir kılmaktadır. AF'si olan hastaların yönetimine yönelik yayınlanan kılavuzlar 1şı̆̆ında orta/ciddi mitral darlık, mekanik protez kapak, gebelik, son dönem böbrek yetmezliği gibi kontraendike durumların yokluğunda YOAK'ların antikoagülan tedavi olarak ilk tercih edilecek ilaçlar olduğu vurgulanmaktadır [5]. RELY (Randomized Evaluation of Long-term Anticoagulation Therapy) çalışması ile AF'si olan hastalarda inmeden korunmada yararı kanıtlanmış olan Dabigatran bu endikasyon ile klinik kullanım onayı almış olan ilk yeni nesil oral antikoagülandır [6]. Plazma ve karaciğerdeki esterazlar ile aktif molekül haline dönüşen Dabigatran direkt trombin inhibitörü olarak etki göstermektedir. Trombositler, normal hemostazın sürdürülmesinde önemli rol oynayan, kanın en küçük ama son derece reaktif bileşenleridirler [7]. Serebrovasküler olaylarda trombüs oluşumunda aktif olarak rol almaktadırlar [8]. Trombosit fonksiyonları dolaylı olarak Mean Platelet Volume (MPV), Plateletcrit (PCT) ve Platelet Distribution Width (PDW) gibi parametreler ile değerlendirilebilmektedir. Hacim olarak büyük olan trombositlerin metabolik olarak da daha aktif oldukları gösterilmiştir [9]. Metabolik olarak aktif olan trombositlerin ilaçlar ile inhibisyonu da akut trombotik olayların önlenmesi adına bir hedef oluşturabilir. Biz de bu çalışmamızda Dabigatran tedavisinin etkinliğinde trombosit fonksiyon göstergesi olan laboratuar parametreleri üzerindeki etkilerini araştırmayı planladık.

\section{Materyal and Metot}

Retrospektif olarak dizayn edilen çalışmamız, üniversitemiz klinik araştırmalar etik kurulunun onayı alınarak Helsinki Deklarasyonunda belirtilen esaslara göre gerçekleştirildi. Çalışmamıza ocak 2018 ve aralık 2019 tarihleri arasında Manisa Celal Bayar Üniversitesi Kardiyoloji polikliniğine başvurup, non valvüler atriyal fibrilasyon tanısı ile endikasyon dahilinde dabigatran tedavisi başlanmış 69 hasta dahil edilmiştir. Hastaların dosyaları taranarak dabigatran başlanmadan önceki ve tedavi altında 6 ay sonraki laboratuar parametreleri değerlendirmeye alındı.

Bilinen valvüler kalp hastalığı, tiroid bozukluğu, otoimmün hastalık, kronik böbrek hastalığı, akut enfeksiyon, kanser ve hemorajik inme öyküsü olan hastalar çalışma dışı bırakıldı.

İstatistiksel değerlendirme SPSS 22.0 İstatistik Paket Programı (SPSS Inc, Chicago, Illinois, ABD) kullanılarak yapıldı. Verilerin normal dağılımı Kolmogorov Smirnov testi ile değerlendirildi. Sayısal değişkenlerden normal dağılım sergileyenler ortalama \pm standart sapma olarak gösterildi. Kategorik değişkenler sayı ve yüzde olarak temsil edildi. Kategorik olmayan değişkenlerde parametrik olanların karşılaştırılmasında student- $T$ testi kullanıldı. $\mathrm{P}<0.05$ değeri istatiksel olarak anlamlı kabul edildi.

\section{Bulgular}

Çalışmaya kriterlere uyan 69 hasta dahil edildi. Yaş ortalaması $69 \pm 9$ olup, hastaların \%62,3'si kadın, \%37,7'si erkek idi. Hastaların \%87'sinde hipertansiyon, $\% 26,1$ 'inde diabetes mellitus, \%17,4'ünde dislipidemi mevcuttu. Sigara kullanım oranı \%2,9 olarak gözlendi. Hastaların \%5,8'inde daha önceden geçirilmiş inme öyküsü mevcuttu. Atriyal fibrilasyonu olan hastalarda inme riskini belirlemek amacıyla kullandığımız ve inme veya geçici iskemik atak öyküsü varlığının 2 puan, kalp yetmezliği, hipertansiyon ve diabetes mellitus varlığının ise 1 'er puan olarak değerlendirildiği $\mathrm{CHADS}_{2}$ skoru çalışma grubumuzda $3,22 \pm 1,14$ olarak saptandı. (Tablo 1).

Tablo 1. Hastaların demografik özellikleri

\begin{tabular}{|l|c|}
\hline Değişkenler & \\
\hline Yaş (ortalama \pm SD) & $69 \pm 9$ \\
\hline Cinsiyet, Kadin; $\mathrm{n},(\%)$ & $43(62.3)$ \\
\hline Hipertansiyon;,$(\%)$ & $60(87)$ \\
\hline Diabetes mellitus; $\mathrm{n},(\%)$ & $18(26.1)$ \\
\hline Dislipidemi; n, (\%) & $12(17.4)$ \\
\hline Sigara;,$(\%)$ & $2(2.9)$ \\
\hline İnme;,$(\%)$ & $4(5.8)$ \\
\hline CHADS 2 skoru (ortalama \pm SD) & $3.22 \pm 1.14$ \\
\hline
\end{tabular}

Dabigatran kullanımını takiben kan parametrelerinin karşılaştırılması Tablo 2'de gösterilmiştir. 6 aylık dabigatran kullanımı sonrasında, başta MPV olmak üzere, platelet sayısı ve diğer trombosit indekslerinde anlamlı bir değişiklik izlenmemiştir.

\section{Tartıșma}

Çalışmamızda AF'de inme riskinin önlenmesinde varfarine alternatif olarak kullanıma giren yeni nesil oral antikoagülanlardan ilki olan dabigatranın platelet fonksiyonları üzerindeki etkisini araştırdık. 6 aylık bir tedavi periyodunda dabigatranın MPV başta olmak üzere, trombosit sayısı ve diğer platelet indeksleri üzerinde anlamlı bir değişikliğe yol açmadığını gözlemledik. Yakın zamanda Duzen ve arkadaşları tarafından yapılan 116 hastanın dahil edildiği fakat hastaların hangi yeni nesil oral antikoagülanları kullandığının belirtilmediği bir çalışmada da MPV ve 
Tablo 2. Kan parametrelerinin Dabigatran tedavisi öncesi ve sonrası karș1laștırılması

\begin{tabular}{|c|c|c|c|}
\hline Değişkenler & Öncesi & Sonrası & $\begin{array}{c}p \\
\text { değeri }\end{array}$ \\
\hline $\mathrm{Hb}\left(\times 10^{3} / \mu \mathrm{L}\right)$ & $\begin{array}{l}13.39 \pm \\
1.67\end{array}$ & $\begin{array}{l}13.32 \pm \\
1.41\end{array}$ & 0.558 \\
\hline RDW (\%) & $\begin{array}{l}13.77 \pm \\
1.81\end{array}$ & $\begin{array}{l}13.74 \pm \\
1.71\end{array}$ & 0.908 \\
\hline $\mathrm{WBC}\left(\times 10^{3} / \mu \mathrm{L}\right)$ & $\begin{array}{l}7.89 \pm \\
2.50\end{array}$ & $\begin{array}{l}7.92 \pm \\
2.38\end{array}$ & 0.903 \\
\hline $\operatorname{PLT}\left(\times 10^{3} / \mu \mathrm{L}\right)$ & $\begin{array}{l}230.24 \pm \\
74.54\end{array}$ & $\begin{array}{l}220.05 \pm \\
56.76\end{array}$ & 0.212 \\
\hline MPV (fL) & $\begin{array}{l}9.24 \pm \\
0.94\end{array}$ & $\begin{array}{l}9.19 \pm \\
1.39 \\
\end{array}$ & 0.798 \\
\hline PCT (\%) & $\begin{array}{l}0.21 \pm \\
0.07 \\
\end{array}$ & $\begin{array}{l}0.21 \pm \\
0.04 \\
\end{array}$ & 0.877 \\
\hline PDW (\%) & $\begin{array}{l}11.63 \pm \\
1.33\end{array}$ & $\begin{array}{l}11.49 \pm \\
1.26\end{array}$ & 0.432 \\
\hline
\end{tabular}

Hb: Hemoglobin; RDW:Red Blood Cell Distribution Width; WBC: White Blodd Cell; PLT: Platelet; PCT: plateletcrit; PDW: Platelet Distribution Width

diğer platelet indekslerinin non valvüler $\mathrm{AF}$ hastalarında tedaviden etkilenmediği saptanmıştır [10]. Bu veriler YOAK'ların AF'de inme riskini önleyici etkilerinde platelet fonksiyonları veya boyutları üzerindeki etkilerinin belirli bir rol oynamadığını düșündürmektedir.

Güncel veriler trombosit hacmindeki ve boyutundaki artışın trombotik ve inflamatuar ortamın varlığını yansitabileceğini düşündürmektedir [11]. Trombosit büyüklüğünün en sik kullanılan ölçüsü olan $\mathrm{MPV}$, trombosit fonksiyonunun bir göstergesi olarak kabul edilmektedir. Daha büyük trombositler metabolik ve enzimatik olarak daha aktiftir ve protrombotik potansiyele sahiptir [12]. Bu nedenle, birçok çalışma MPV ile koroner arter hastalığ 1 , stent restenozu riski, periferik arter hastalığ sendrom gibi trombotik bozukluklar arasındaki ilişkiyi araştırmıştır [13]. Örneğin, Ozkan ve arkadaşları MPV'nin genç hastalarda akut miyokard enfarktüsünün bağımsız prediktörlerinden biri olduğunu bulmuştur [14]. Atriyal fibrilasyonlu hastalarda ve inme hastalarında da benzer çalışmalar bildirilmiştir.

Atriyal fibrilasyonun iskemik inmenin önemli bir nedeni olduğunu ve meydana geldiğinde inme riskinde yaklaşı beş kat artışa yol açtığını bilmekteyiz [15]. Atriyal fibrilasyonun prokoagülan ve protrombotik durumuna bağlı gelișen tromboembolik komplikasyonlar bildirilmiştir. Bununla birlikte, yeni ilaç ve cihazların üretimine rağmen, bu risk tamamen ortadan kalkmamaktadır. Bu nedenle, riskli hastaların erken tespiti çok önemlidir. MPV bu bağlamda riskli hasta grubunu belirlemekte bir belirteç olarak kullanılabilir. Colkesen ve arkadaşlarının yapmış oldukları çalışmada paroksismal AF'si olanlarda normal popülasyona oranla MPV değerlerinin daha yüksek olduğu saptanmıștır [16]. Choudhury ve arkadaşları tarafindan yapılan çalışmada ise permenant AF'si olan hastalarda, paroksismal AF'si olanlara göre daha yüksek MPV seviyelerinin olduğu gösterilmiştir [17]. İnme hastalarında MPV ie yapılmış olan çalışmalara bakacak olursak; MPV düzeyinin akut iskemik inmede yüksek olduğu ve de inme hastalarında progoz ile ilişkli olduğu gösterilmiştir $[18,19]$. 3134 hastanın dahil ediliği ve yaklaşık 4 yıl boyunca takip edildiği PROGRESS çalışmasında MPV, inme veya geçici iskemik atak öyküsü olan bireyler arasında inme riskinin bağımsız bir prediktörü olarak saptanmıştır [19]. AF hastalarında sol atriyum ve sol atriyal apendiksin inmenin gelişimi ile ilgili en yaygın kardiyak emboli bölgeleri olduğu iyi bilinmektedir. Yapılan bir çalışmada AF'si olan hastalarda artan MPV'nin sol atriyal staz ile ilişkili olduğu bildirilmiştir [20]. AF'si olan 140 hastanın dahil edildiği bir çalışmada, MPV düzeyleri 9,4 fL'den yüksek olan hastaların dört kat daha fazla inme riskine sahip oldukları belirtilmiștir [21]. Bayar ve arkadaşlarının yapmış olduğu bir diğer çalışmada ise 9,85 fL MPV değeri inme için cuttoff değer olarak saptanmıştır [22].

Literatüre baktığımızda bazı ilaçların MPV üzerine olan etkilerinin araştırıldığı çalışmalar da mevcuttur. Paroksismal AF'de asetil salisilik asit (ASA), stabil koroner arter hastalığ 1 olanlarda ise ikili antiplatelet tedavi (ASA + Klopidogrel) kullanımının MPV üzerine anlamlı bir etkisinin olmadığı saptanmıştır [16, 23]. Diğer taraftan nonvalvüler atriyal fibrilasyonu olan hastalarda varfarin ile yapılmış bir çalışmada ise International Normalized Ratio (INR) düzeyi 2,0-3,0 aras1 olan hastaların kontrol grubuna (sinüs ritmi) göre MPV, PDW ve PCT değerlerinde anlamlı bir değişiklik olmadığı tespit edilmiştir [24].

\section{Sonuç}

Çalışma verilerimiz ışı̆̆ında Dabigatran'ın AF'de inme ve tromboembolinin önlenmesinde, platelet indeksleri üzerine olan etkisinin bir anlam ifade etmediği görülmektedir. Varfarinin aksine doz ayarı gerektirmeyen ve standard dozlarda kullanilan YOAK'ların etkinlik takibinde platelet indeksleri uygun birer parametre gibi görülmemektedir ama diğer yeni nesil ajanlar ile yapılacak olan çalışmalara ihtiyaç vardır.

\section{References}

1. Wolf, PA, Abbott, RD, Kannel, WB, Atrial fibrillation as an independent risk factor for stroke: the Framingham Study, Stroke, 1991, 22(8), 983-8

2. Ruff, CT, Giugliano, RP ve ark, Comparison of the efficacy and safety of new oral anticoagulants with warfarin in patients with atrial fibrillation: a meta-analysis of randomised trials, Lancet (London, England), 2014, 383(9921), 955-62.

3. Camm, AJ, Breithardt, G ve ark, Real-life observations of clinical outcomes with rhythm- and rate-control therapies for atrial fibrillation RECORDAF (Registry on Cardiac Rhythm Disorders Assessing the Control of Atrial Fibrillation), Journal of the American College of Cardiology, 2011, 58(5), 493-501.

4. Rienstra, M, Damman, K, ve ark, Beta-blockers and outcome in heart failure and atrial fibrillation: a meta-analysis, JACC Heart failure, 2013, 1(1), 21-8.

5. January, CT, Wann, LS ve ark, 2019 AHA/ACC/HRS Focused Update of the 2014 AHA/ACC/HRS Guideline for the Management of Patients With Atrial Fibrillation: A Report of the American College of Cardiology/American Heart Association Task Force on Clinical Practice Guidelines and the Heart Rhythm Society in 
Collaboration With the Society of Thoracic Surgeons, Circulation, 2019, 140(2), e125-e51.

6. Connolly, SJ, Ezekowitz, MD ve ark, Dabigatran versus warfarin in patients with atrial fibrillation, The New England journal of medicine, 2009, 361(12), 1139-51.

7. Korniluk, A, Koper-Lenkiewicz, OM, Kaminska, J, Kemona, H, Dymicka-Piekarska, V, Mean Platelet Volume (MPV): New Perspectives for an Old Marker in the Course and Prognosis of Inflammatory Conditions, Mediators of inflammation, 2019, 2019, 9213074.

8. Fateh-Moghadam, S, Htun, P ve ark, Hyperresponsiveness of platelets in ischemic stroke, Thrombosis and haemostasis, 2007, 97(6), 974-8

9. Han, JY, Choi, DH ve ark, Stroke or coronary artery disease prediction from mean platelet volume in patients with type 2 diabetes mellitus, Platelets, 2013, 24(5), 401-6.

10. Duzen, IV, Oguz E ve ark, Effect of new oral anticoagulants on platelet indices in non-valvular atrial fibrillation patients, Herz 2019.

11. Gasparyan, AY, Ayvazyan, L, Mikhailidis, DP, Kitas, GD, Mean platelet volume: a link between thrombosis and inflammation? Current pharmaceutical design, 2011, 17(1), 47-58.

12. Bath, PM, Butterworth, RJ, Platelet size: measurement, physiology and vascular disease, Blood coagulation \& fibrinolysis : an international journal in haemostasis and thrombosis, 1996, 7(2), 157-61.

13. Vizioli, L, Muscari, S, Muscari, A, The relationship of mean platelet volume with the risk and prognosis of cardiovascular diseases, International journal of clinical practice, 2009, 63(10), 1509-15.

14. Ozkan, B, Uysal, OK et al, Relationship between mean platelet volume and atherosclerosis in young patients with ST elevation myocardial infarction, Angiology, 2013, 64(5), 371-4.

15. Benjamin, EJ, Wolf, PA, D'Agostino, RB, Silbershatz, H, Kannel, WB, Levy, D, Impact of atrial fibrillation on the risk of death: the Framingham Heart Study, Circulation, 1998, 98(10), 946-52.

16. Colkesen, Y, Acil, T et al, Mean platelet volume is elevated during paroxysmal atrial fibrillation: a marker of increased platelet activation? Blood coagulation \& fibrinolysis : an international journal in haemostasis and thrombosis, 2008, 19(5), 411-4.

17. Choudhury, A, Chung, I, Blann, AD, Lip, GY, Platelet surface CD62P and CD63, mean platelet volume, and soluble/platelet Pselectin as indexes of platelet function in atrial fibrillation: a comparison of "healthy control subjects" and "disease control subjects" in sinus rhythm, Journal of the American College of Cardiology, 2007, 49(19), 1957-64.

18. Butterworth, RJ, Bath, PM, The relationship between mean platelet volume, stroke subtype and clinical outcome, Platelets, 1998, 9(6), 359-64.

19. Bath, P, Algert, C, Chapman, N, Neal, B, Association of mean platelet volume with risk of stroke among 3134 individuals with history of cerebrovascular disease, Stroke, 2004, 35(3), 622-6.

20. Providencia, R, Faustino A et al, Mean platelet volume is associated with the presence of left atrial stasis in patients with non-valvular atrial fibrillation, BMC cardiovascular disorders, 2013, 13, 40.

21. Turfan, M, Erdogan, E et al, Usefulness of mean platelet volume for predicting stroke risk in atrial fibrillation patients, Blood coagulation \& fibrinolysis : an international journal in haemostasis and thrombosis, 2013, 24(1), 55-8.

22. Bayar, N, Arslan, S et al, Usefulness of mean platelet volume for predicting stroke risk in paroxysmal atrial fibrillation patients, Blood coagulation \& fibrinolysis : an international journal in haemostasis and thrombosis, 2015, 26(6), 669-72.

23. Guthikonda, S, Alviar, CL et al, Role of reticulated platelets and platelet size heterogeneity on platelet activity after dual antiplatelet therapy with aspirin and clopidogrel in patients with stable coronary artery disease, Journal of the American College of Cardiology, 2008, 52(9), 743-9.

24. Arik, OZ, Ozkan, B et al, Relationship between platelet indices and international normalized ratio in patients with non-valvular atrial fibrillation, Platelets, 2014, 25(5), 311-6. http://edergi.cbu.edu.tr/ojs/index.php/cbusbed isimli yazarın CBU-SBED başlıklı eseri bu Creative Commons Alıntı-Gayriticari4.0 Uluslararası Lisansı ile lisanslanmıştır.

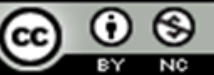

